\title{
Trait Anger, Employee Work Behaviors, and the Moderating Role of Problem Focused-Coping
}

\author{
Hakan Ozcelik ${ }^{1}$ \& Laura Riolli ${ }^{1}$ \\ ${ }^{1}$ College of Business Administration, California State University, Sacramento, USA \\ Correspondence: Hakan Ozcelik, College of Business Administration, California State University, Sacramento, CA, \\ 95816-8099, USA.
}

Received: June 9, 2015

Accepted: June 23, 2015

Available online: July 21, 2015

doi:10.11114/ijsss.v3i5.872

URL: http://dx.doi.org/10.11114/ijsss.v3i5.872

\begin{abstract}
This study aims to analyze the moderating role of problem-focused coping style in the relationship between trait anger and employees' withdrawal and taking-charge behaviors. Our sample included 254 employees from two middle-sized organizations, i.e. a medical facility and a financial company, in Northern California. To reduce the common-source and desirability biases, the data regarding taking-charge behaviors were collected from the employees' supervisors. Our results showed that employees with higher level of trait anger were more likely to engage in taking-charge behaviors, such as identifying and pursuing work-related problems. In addition, trait anger instigated withdrawal behaviors if the employees reported lower levels of problem-focused coping. In contrast, when employees were higher on problem-focused coping, their trait anger was not significantly related to withdrawal behaviors. These results suggest that, when employees take on a more problem-focused approach to manage their stress at work, their trait anger could work for the benefit of these employees and their organization by driving them to identify and solve work-related problems. Our study revealed that trait anger, in itself, is not necessarily a functional or dysfunctional employee characteristic and delineated the moderating role of problem-focused coping style in the relationship between trait anger and work behaviors.
\end{abstract}

Keywords: emotions, anger, behaviors, trait anger

"Anybody can become angry; that is easy; but to be angry with the right person, at the right time, for the right purpose, and in the right way, that is not within everybody's power; that is not easy" (Aristotle, 350 BCE, 2004: p. 150).

\section{Introduction}

Organizational life is entwined with a wide range of discrete emotions, with distinct psychological processes and action tendencies (Lazarus and Cohen-Charash, 2004) and thus different implications for organizational outcomes. The self-management of these emotions can have a differential impact on employees' behavior and role performance (Brotheridge and Lee, 2003). Thus, at both the theoretical and empirical levels, discrete emotions in organizations deserve closer attention (Barsade and Gibson 2007). One such emotion with extensive implications for organizational life is anger. Anger is a prevalent emotion that can be experienced by most people in organizations. Indeed, a recent study has found that almost one in four Americans experience chronic anger in the workplace (Pearson et al., 2000). Moreover, previous studies on trait anger have established that people's experience of anger has a predispositional basis (Wilkowski and Robinson, 2010; Deffenbacher et al., 1996; Deffenbacher, 1992; Spielberger et al., 1983).

Trait anger refers to a person's inherent tendency to experience frequent and pronounced episodes of this emotion, across situations (Spielberger et al., 1983). People with higher trait-anger levels tend to perceive a wider range of situations as anger provoking and experience more intense elevations of anger in anger-eliciting situations (Deffenbacher, 1992). Studies have also found trait anger to be related to higher levels of ambulatory and resting blood pressures (Schum et al., 2003; Suls et al. 1995). Considering that anger is a high activation emotion (Collins, 1990), which mobilizes a person's energy and guides their mental and physical activity (Izard, 1991), it is plausible to argue that trait anger can systematically influence employees' responses to work events and drive their actions across work situations. Thus, exploring the role of trait anger in organizations can improve our understanding about some of the underlying mechanisms that explain the relationships between emotion and work behaviors. However, to date, there has been very little attempt in organizational behavior research to analyze anger as an affective trait, with the exception of a 
few studies that examined the relationship between trait anger and workplace aggression (e.g. Hepworth and Towler, 2004; Fox, Spector, and Miles, 2001; Douglas and Martinko, 2001). Instead, the extant research has mostly informed us about anger in organizations by considering it as a transient, situation-based, episodic affective state (please see Gibson and Callister, 2010, for a review). With an aim to fill this gap, we have analyzed the behavioral outcomes of trait anger in organizations.

When exploring the relationship between trait anger and work behaviors, we employed a perspective that draws on an analysis of previous research, which suggests that anger, in itself, is not necessarily a functional or dysfunctional emotion: On one hand, anger may result in hostility, distraction, and lack of personal control (Berkowitz, 1990; Booth \& Mann, 2004). On the other hand, anger can mobilize energy for action and induce a sense of vigor and self-confidence (Izard, 1991), make employees more capable of defending themselves (Lindenbaum and Fielden, 2011), and increase managers' ethical awareness and motivation when making organizational decisions (Mickel and Ozcelik, 2008). In line with these views, recent experimental and theoretical studies suggest that a more complete understanding of the relationship between anger and employee behaviors requires a fine-tuned approach that takes into account possible factors that might influence this relationship. In their theoretical study, for instance, Geddes and Callister (2007) have argued that anger can result in both functional and dysfunctional organizational outcomes, depending on organizational observers' judgments and reactions to the expression of an employee's anger. In their experimental study, Van Kleef and Côté (2007) have empirically explored the positive and negative interpersonal consequences of the expression of anger and found that the consequences of anger depends on the context in which it is expressed and the power of the persons who observe it. Similarly, in their review of experimental studies analyzing anger in negotiation settings, Van Kleef et al. (2008) suggested that anger expressions can elicit both competition and cooperation between the parties, depending on such factors as the level of their interdependency and the justifiability of anger expression.

Drawing on the studies mentioned above, it is plausible to argue that trait anger has the potential to trigger both functional and dysfunctional behaviors in organizations, depending on how an employee tends to act on their anger and respond to their environment in anger-eliciting situations. Since the experience of anger usually comes with an increased level of physical arousal and stress (Berkowitz, 1990), the nature of an employee's tendency to cope with stress should play an important role in how the employee generally responds to their anger, and thus could explain the relationship between trait anger and behavioral outcomes. Thus, we have developed and empirically tested a model to analyze the moderating role of an employee's coping style in the relationship between trait anger and the employee's functional and dysfunctional work behaviors. The model tested in this study goes against the conventional wisdom that anger needs to be avoided in organizations at all costs; and aims to provide a more fined-tuned analysis of anger, as a predisposition, in organizational life by delineating whether and when trait anger can be related to negative and positive work outcomes.

\section{Theory and Hypotheses}

When analyzing an employee's work behaviors, we have considered both functional and dysfunctional outcomes that are potentially related to an employee's trait anger, including taking charge (Morrison and Phelps, 1999) and withdrawal behaviors (Aquino et.al, 1999), respectively. Taking charge refers to voluntary and constructive efforts to affect organizationally functional change with respect to how work is executed within the contexts of their jobs, work units or organizations (Morrison and Phelps, 1999). Withdrawal work behaviors, on the other hand, refer to actions that employees engage in to avoid work by violating organizational norms around duties, such as leaving work early without getting permission and taking undeserved breaks to avoid work (Aquino, Lewis, and Bradfield, 1999).

\subsection{Trait Anger and Taking-charge Behaviors}

As a reflection of their predisposition, some employees tend to experience anger more easily and intensely than others (Wilkowski and Robinson, 2010). Work environments involve several anger-eliciting factors, some of which include inefficient task procedures and managerial policies that hamper an employee's ability to get the job done, unfair treatments, disrupting coworkers or work events, and morally irresponsible coworker behaviors such as being lazy, taking advantage of others, and being rude to clients (Fitness, 2000). Although such factors can evoke anger in any employee, employees with higher trait anger will be more likely to experience anger when they encounter such work problems. The appraisal theory of emotions (Lazarus, 1991; Frijda, 1987) suggests that people interpret emotional-eliciting events through a process of cognitive evaluation, involving the steps of primary and secondary appraisal. Primary appraisal is the first cognitive response of an individual to the increased level of arousal and it involves an assessment of whether a specific event is good or bad and how relevant it is to one's well-being. This theory suggests that anger can serve an adaptive function by increasing an individual's level of bodily arousal and cognitive attention about a problematic situation and by providing information about the appraisal of this situation with respect to his or her concerns (Frijda, 1986). 
We argue that those employees who are higher on trait anger will be more receptive to the cues about potential problems in their work environment because of the arousal associated with their experienced anger. Thus, employees with higher levels of trait anger would more strongly respond to work-related issues that elicit anger, even if these issues are beyond the scope of the employee's formal roles and duties. A faulty work procedure that is gone unnoticed by other employees, for instance, would catch the attention of an employee with higher trait anger as he or she experiences an increase in their level of arousal. It has been also suggested that anger increases people's courage to express their opinions about work-related issues (Lindebaum and Fielden, 2011) and determination to solve work-related problems (Mickel and Ozcelik, 2008). Thus, it is plausible to argue that higher trait anger will make an employee more energized to bring out problematic work issues to the agenda, more determined to seek possible solutions for these issues, and more courageous to deal with potential conflicts that might impede progress towards these possible solutions. This proactive psychological state, in turn, will motivate the employee to seek improved ways to perform his/her work activities and will increase his or her motivation to go extra mile and take charge to improve their work environment. Thus:

Hypothesis-1: Employees with higher trait anger levels will be more likely to engage in taking charge behaviors.

\subsection{Trait Anger and Withdrawal Behaviors}

The high level of tension associated with anger is likely to drive people to get engaged with behaviors to self-regulate their anger (Frijda, Kuipers, and ter Schure, 1989). Previous research has shown that self-regulation of emotions depletes people's psychological resources (Gross and John, 2003). Beal, Weiss, Barros, and MacDermid (2005) have argued that emotional-regulation processes are likely to shift an employee's focus from their task environment to off-task concerns and activities and thereby deplete their cognitive resources. Although employees with higher trait anger will have a stronger motivation to take charge to improve their work environment as discussed above, these employees would also have a stronger need to self-regulate their emotions and replenish their psychological resources, as compared to others. Therefore, these employees would be more likely to engage in withdrawal behaviors, such as calling in sick when not being really ill, taking undeserved breaks, and leaving work early without permission, to replenish their resources.

Since emotional regulation activities such as venting and rumination can be considered as inappropriate by others in the work environment (Ashforth and Humphrey, 1995), the withdrawal behaviors could also result from the employees' motivation to seek non-work venues to engage in these emotion-regulation activities. Thus, we predict the following hypothesis:

\section{Hypothesis-2: Employees with higher trait anger levels will be more likely to engage in taking charge behaviors.}

\subsection{Moderating Role of Problem-Focused Coping Style for Taking-charge Behaviors}

Anger is a very strong emotion that creates an inner stress and tension in the person experiencing it and drives the person's behavior depending on how he or she acts on this tension (Izard, 1991). Therefore, to more fully explore the behavioral outcomes of trait anger in organizations, it is important to understand the underlying factors that influence how employees generally act on the stress and tension associated with the anger they experience.

The appraisal theory of emotions suggests that, after people interpret a specific emotion such as anger through the primary appraisal process that we described earlier, they engage in a secondary appraisal process in which they interpret the cues from the environment to analyze the emotion-eliciting events and evaluate their alternative courses of action (Smith, Haynes, Lazarus, Pope, 1993). Previous studies have identified a person's coping potential and his or her expectancy about whether he or she could improve the situation as a key dimension of this appraisal process, which in turn influences the person's behavioral responses to their emotion (e.g., Lazarus, 1991; Smith and Ellsworth, 1985). According to these studies, depending on their coping styles, people make a conviction about whether or not they can act on the emotion-eliciting event to improve a problematic situation. Prior research in the stress literature suggests that people are more likely to believe that they can improve an emotion-eliciting situation when they have a stronger problem-focused style, which involves behaviors aiming to act on the source of stress, such as seeking ways to change the environment or solve the stress-creating problem (Lazarus and Folkman, 1984). Lazarus (1999) suggests that there are relatively stable differences among individuals with respect to the degree to which they employ problem-focused coping style in their daily lives. In this study, we argue that an employee's level of problem-focused coping will influence how they act on the stress and tension associated with their trait anger and thus will moderate the relationship between trait anger and employees' behavior.

Problem-focused coping style is characterized by a general state of eagerness to achieve goals, which motivates people to obtain information about what to do and mobilizes their actions for the purpose of changing the problematic person-environment relationship (Lazarus, 1991). We argue that, for those employees with higher levels of problem-focused coping, the positive relationship between trait anger and taking charge behaviors will be stronger 
because these employees will feel more eager and optimistic about controlling the job environment and tackling work-related issues that provoke anger, as compared to those with a lack of tendency for problem-focused coping. Although emotion-focused coping (i.e., regulating one's emotional responses instead of seeking to reduce or eliminate stressor) has often been studied together with problem-focused coping, we did not include it in this study because previous research has shown that the measurement model for emotion-focused coping is complex, including both positive and negative behaviors, which makes it difficult to conceptualize emotion-focused coping as a unidimensional construct (Stanton, Danoff-Burg, Cameron, \& Ellis, 1994; Stanton, Kirk, Cameron, \& Danoff-Burg, 2000; Terry \& Hyness, 1998).

Hypothesis-3: Problem-focused coping will moderate the relationship between trait anger and taking-charge behaviors such that the relationship will be more positive for those who have a higher tendency for problem-focused coping.

\subsection{Moderating Role of Problem-Focused Coping Style for Withdrawal Behaviors}

Problem-focused coping will also influence the relationship between trait anger and employees' withdrawal behaviors. Considering that problem-focused coping increases an employee's sense of control in work environment, for employees with a lower tendency for problem-focused coping, the anger experienced about work related issues will be more likely to be coupled with a sense of lack of control. Accordingly, the level of tension associated with anger and the need to self-regulate anger will be higher for those employees with lower levels of problem-focused coping. Thus, when they have lower tendency for problem-focused coping, as a response to the relatively more taxing impact of the anger they experience at work, employees with higher trait anger will be more likely to engage in withdrawal work behaviors, such as leaving work early without getting permission and taking undeserved breaks to avoid work.

There is also empirical evidence that expressing anger can be strategically used to influence others by using anger "to make a point," "get attention," or make other people "recognize the seriousness of the conversation" 44(Mickel and Ozcelik, 2008). For instance, an employee who strategically expresses anger to correct a faulty procedure could be taken more seriously by other employees as compared to others who do not express any anger about the issue or who express their anger non-strategically (e.g. venting). Since employees with a stronger problem-focused coping tendency will feel more eager and optimistic about controlling their job environment, they would be more inclined to strategically express their anger to others and channel their energy to solve work related problems; and less inclined to engage in non-work related activities to self-regulate their anger. Thus, for those employees with higher levels of problem-focused coping, trait anger should less strongly drive the employees to engage in withdrawal behaviors. The preceding discussion leads us to the following hypotheses:

Hypothesis-4: Problem-focused coping will moderate the relationship between trait anger and withdrawal behaviors such that the relationship will be more positive for those who have a lower tendency for problem-focused.

\section{Methods}

\subsection{Sample and Design}

Our sample included employees and their managers from two middle-sized organizations in Northern California. One company was a medical facility and the other company was a technologically advanced financial group. Surveys were sent to 200 employees at each organization. The data regarding the employees' extra role behaviors were collected from the supervisor of employees, to reduce the common-source and desirability biases.

A total of 161 subordinates and their respective supervisors from the financial group returned completed surveys, with a response rate of $80.5 \%$. A total of 100 employees and their supervisors from the medical facility returned completed surveys with a response rate of 50\%. After dropping 7 cases with missing information, we used data from 154 employees from the financial group and 100 employees from the medical facility and their respective supervisors. The sample consisted of 254 employees (44\% male and 56\% female). On average, subordinates had 14.98 years of work experience (s.d. $=10.95$ ), of which they spend an average of 5.55 years $($ s.d. $=4.94)$ in their current department. The distribution of respondents' education level was as follows: $16 \%$ high-school degree, $49 \%$ some college degree, $23 \%$ bachelors degree, and $12 \%$ graduate degree. The respondents came from a variety of professional backgrounds such as administrative/clerical, technical, finance/accounting, and clinical services.

\subsection{Procedure}

A contact person from the Human Resources Management (HRM) department of the two participating companies distributed the survey packages to employees and their supervisors. To ensure that their responses to the survey would remain confidential, the respondents returned sealed envelopes to the HRM contact person. After receiving the employee responses their respective managers were contacted by the HRM contact person and distributed the questionnaires which assessed each subordinate's performance regarding extra role behaviors. The supervisors returned their surveys about 4 weeks after data were collected from the employees. 


\subsection{Measures}

Subordinates and supervisors used a 7 -point scale $(1=$ strongly disagree, $7=$ strongly agree $)$ to answer all the questions.

\subsubsection{Trait Anger}

Subordinates reported their trait anger using the 10-item scale developed by Speilberger et al., (1983). Sample items included: "I am a hot-headed person.", and "I am quick tempered." The internal reliability of this measure was 0.78 .

\subsubsection{Problem-Focused Coping}

We used Lazarus and Folkman's (1984) 9-item scale to measure problem-focused coping. Participants were asked to describe how they usually respond when they face a problem or stressful situation in their work by indicating their agreement with each of the scale items provided to them. Sample items included: "I often make a plan of action and follow it", and "I try to analyze the problem in order to understand it better" $(\alpha=.70)$.

\subsubsection{Taking-charge Behaviors}

Each subordinate's supervisor completed Morrison and Phelps's (1999) 8-item scale to measure the employee's taking charge behaviors at work. Sample items included: "Trying to implement solutions to pressing problems.", and "Trying to correct faulty procedures or practices" $(\alpha=.82)$.

\subsubsection{Withdrawal Behaviors}

Subordinates completed a 5-item scale from Aquino et al. (1999). Sample items included: "Taking undeserved breaks to avoid work", "Leaving work early without permission", "Intentionally arriving late for work". The internal reliability of the scale was 0.84 .

\subsubsection{Control Variables}

We controlled our analyses for a set of demographic variables that could be related to taking-charge and withdrawal behaviors and thus might confound the relationships we have posited, including the employee's age, gender, education, and departmental tenure. We have also controlled our results for the amount of time an employee spends with his or her supervisor in a week because spending more time with supervisor would make it more difficult to engage in withdrawal behavior. In addition, we have included an employee's level of perceived job stress as a control variable in the study since it could confound the relationship between trait anger and employee behaviors. We measured perceived work stress by using a 4-item scale from Endler and Parker (1990), including items such as: "Being stressed out comes with my job", and "I frequently get stressed at work". The internal reliability of this scale was 0.75 .

\section{Results}

We used hierarchical multiple regression analysis to test our hypotheses, following the procedures suggested by Baron and Kenny (1986). For each dependent variable, we ran a separate regression analysis. For each analysis, we first entered our control variables in Step-1, the main effects of independent variable (i.e. trait anger) and the moderating variable (i.e. problem-focused coping) in Step-2, and the interaction of trait anger and the moderator variable in Step-3. Following Aiken and West (1991), we centered the trait anger and problem-focused coping variables prior to computing interaction terms. The results for our analyses testing the study's hypotheses are presented in Table 2.

Table 1. Results of multiple regression analyses testing the study's hypotheses

\begin{tabular}{|c|c|c|c|c|c|c|}
\hline \multirow{2}{*}{$\begin{array}{l}\text { Variables } \\
\text { Control Variables }\end{array}$} & \multicolumn{3}{|c|}{ Taking-charge Behaviors } & \multicolumn{3}{|c|}{ Withdrawal Behaviors } \\
\hline & Step 1 & Step $2(\mathrm{H} 1)$ & $\begin{array}{l}\text { Step } 3 \\
\text { (H3) }\end{array}$ & Step 1 & $\begin{array}{l}\text { Step } 2 \\
(\mathrm{H} 2)\end{array}$ & $\begin{array}{l}\text { Step } 3 \\
(\mathrm{H} 4)\end{array}$ \\
\hline Age & -.01 & -.01 & -.01 & $-.18 *$ & $-.17 *$ & $-.18^{*}$ \\
\hline Gender & .10 & .10 & .10 & .13 & $.15 *$ & $.15^{*}$ \\
\hline Education & .05 & .04 & .03 & -.12 & $-.13^{*}$ & $-.14 *$ \\
\hline Tenure & -.10 & -.11 & -.11 & $.32 * *$ & $.30 * *$ & $.29 * *$ \\
\hline Time with supervisor & .09 & .08 & .09 & $-.15^{*}$ & $-.20 * *$ & $-.18 * *$ \\
\hline Perceived work stress & -.08 & -.13 & -.12 & .08 & .02 & .02 \\
\hline \multicolumn{7}{|l|}{ Main Effects } \\
\hline Trait Anger (TA) & & $.18^{*}$ & $.17 *$ & & $.25 * *$ & $.23 * *$ \\
\hline Problem-focused coping (PC) & & -.03 & -.03 & & $-.30 * *$ & $-.30 * *$ \\
\hline \multicolumn{7}{|l|}{ Two-way Interaction } \\
\hline TA $x$ PC & & & -.07 & & & $-.12 *$ \\
\hline $\mathrm{F}$ & 1.69 & $2.14^{*}$ & $1.98 *$ & $5.39 * *$ & $12.06^{* *}$ & $12.93 * *$ \\
\hline $\mathrm{R}^{2}$ & .05 & $.09 *$ & $.09 *$ & $.14 * *$ & $.34 * *$ & $.36^{* *}$ \\
\hline Adjusted $\mathrm{R}^{2}$ & .02 & $.05 *$ & $.05 *$ & $.12 *$ & $.32 *$ & $.34 * *$ \\
\hline Change in $\mathrm{R}^{2}$ & & $.03 *$ & .00 & & $.20 * *$ & $.02 *$ \\
\hline
\end{tabular}


$* \mathrm{p}<.05 ; * * \mathrm{p}<.01$

Our first hypothesis predicted that trait anger will be positively related to taking-charge behaviors. As shown in the columns presenting the results of regression analysis predicting taking-charge behaviors in Table 2, when trait anger was entered in the analysis in Step 2, it had a significant positive relationship with taking-charge behaviors $(\beta=.18$, $\mathrm{p}<.05)$. Thus, our first hypothesis was supported.

Our second hypothesis predicted that trait anger will be positively related to withdrawal behaviors. The results of regression analyses testing this hypothesis, presented in Table 2, showed that when trait anger was entered in the regression model in Step-2, it had a significant positive relationship with withdrawal behaviors $(\beta=.25, \mathrm{p}<.05)$, providing support for the second hypothesis.

Our third hypothesis predicted that problem-focused coping will moderate the relationship between trait anger and taking-charge behaviors. As shown in the columns presenting the results of regression analysis predicting taking-charge behaviors in Table 2, the interaction term (Trait Anger x Problem-Focused Coping) was not significant when it was entered in Step-3. Thus, our third hypothesis was not supported. A notable finding from this analysis is that, in Step-3, trait anger remained significant in the regression model $(\beta=.17, \mathrm{p}<.05)$ and problem-focused coping was not significant. These results indicate that employees who are higher on trait anger are more likely to engage in taking-charge behaviors, regardless of their level of problem-focused coping style.

Our fourth hypothesis predicted that problem-focused coping will moderate the relationship between trait anger and withdrawal behaviors. The results in Table 2 show that the interaction term (Trait Anger x Problem-Focused Coping) in the equation predicting withdrawal behaviors was significant $(\beta=-.12 *, \mathrm{p}<.05)$. Following Aiken and West (1991), we conducted a simple slope analysis to examine the relationship between trait anger and withdrawal behaviors at high and low levels of problem-focused coping, i.e. two standard deviations below and above the mean. Figure 1 graphically depicts the results of the interaction. As predicted, the relationship between trait anger and withdrawal behaviors was more positive for those with low problem-focused coping. Indeed, the results indicated that this relationship was not significant for those with high problem-focused coping.

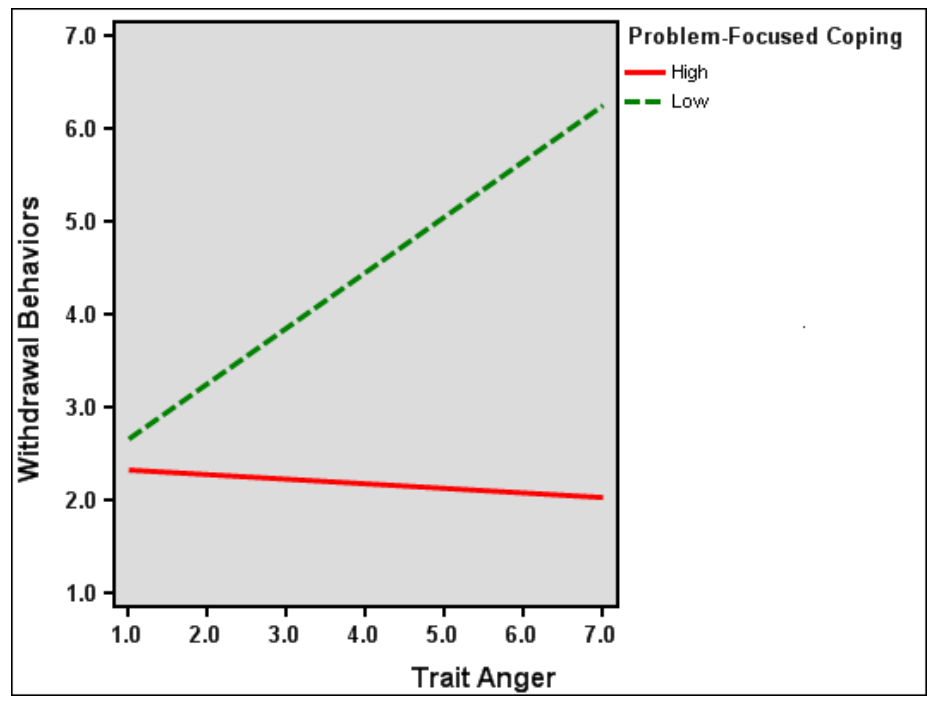

Figure 1. Problem-Focused Coping as Moderator between Trait Anger and Withdrawal Behaviors (H-4)

\section{Discussion}

Our study has explored trait anger in organizations and revealed how it can lead to both positive and negative behaviors at the same time. Specifically, trait anger influenced the employees' likelihood of identifying and pursuing work-related problems, i.e. taking-charge behaviors, and yet at the same time instigates withdrawal behaviors if the employees could not manage the tensions associated with their anger in effective ways by utilizing problem-focused coping strategy. Moreover, when employees were high on problem-focused coping, trait anger was positively related to taking charge behaviors and was not significantly related to withdrawal behaviors. These results suggest that, when employees take on a more problem-focused approach to manage their stress at work, their trait anger could work for the benefit of these employees and their organization by driving them to identify and solve work-related problems.

In this study, we focused anger at the dispositional level, an area which has received very little attention in research on emotions in organizational behavior. Previous research has studied anger mostly as an episodic emotion and the research that focused on trait anger portrayed it by mostly focusing on aggressive behaviors 47 (Gibson and Callister, 
2010). Our study extends the emotions literature, and particularly that on anger in organizations, in three ways. First, our results showed that, apart from aggression, there could be less visible and more silent responses associated with anger, such as the withdrawal behaviors analyzed in this study, which could slowly but gradually undermine an organization's task environment. These results open up a path for future research that can explore the relationship of trait anger to a wider range of work behaviors and attitudes to more fully understand anger as a dispositional factor in organizational behavior.

Second, the results of our study highlighted that anger can play a significant role in organizational context as a dispositional factor as well as an episodic emotion, with potential relationships to not only dysfunctional but also functional outcomes. To our knowledge, there has been no previous research that empirically explored the functional behavioral outcomes of trait anger in organizations. By demonstrating the relationship between trait anger and taking-charge behaviors, our study opens a path for future research to further explore other possible functional outcomes of trait anger, such as ethical behaviors, voice, and sensitivity to fairness. For instance, considering that anger increases ethical awareness (Mickel and Ozcelik, 2008), future research can explore whether an employee with higher trait anger will be more responsive to the unfair treatment of other employees and will be more likely to engage in prosocial behaviors to help these employees. Future research can also analyze whether and how trait anger is related to an employee's in-role performance and the possible moderating factors in this relationship, considering that taking charge behaviors can potentially distract an employee from day-to-day task activities. Additionally, future research can focus on the interaction between trait anger and state anger to examine the differences between employees with high and low levels of trait anger with respect to how they perceive anger-provoking situations and behaviorally respond in these anger episodes.

Third, our results extend the theory about anger by also improving our understanding about the psychological mechanisms to delineate when trait anger is related to functional or dysfunctional behaviors. In a recent study reviewing research on anger in organizations, Gibson and Callister (2010) have proposed an episodic model of anger suggesting that trait anger should influence the degree to which individuals perceive work events to be problematic and the way they respond to these anger-eliciting events. Our results suggest that trait anger does heighten an employee's perceptions about work related problems, as could be inferred from the positive relationship between trait anger and taking charge behaviors. Our results also show, however, that trait anger, in itself, does not drive an employee to negatively respond to these problems. Rather, an employee's level of problem-focused coping plays a moderating role in determining whether trait anger will drive employees to negatively respond to work problems by engaging in withdrawal work behaviors.

The results of our study should be interpreted in light of its limitations. One limitation is the possibility of social desirability bias in employees' reports regarding their trait anger and withdrawal behaviors. Another limitation is the possibility of restriction of range in our measurement of trait anger in the sense that our sample might not include sufficient number of employees with extreme levels of trait anger. It could be argued that, employees with extreme levels of trait anger would be less likely to engage in taking charge behaviors, which might yield a curvilinear relationship between trait anger and taking charge behaviors rather than the positive relationship we have found in this study. Despite these limitations, however, there was sufficient variance in both of these variables to be able to obtain significant results supporting the hypotheses of our study.

Our study provides insights also for managerial practice by showing that trait anger could lead to both functional and dysfunctional behaviors, depending on how employees manage their stress. Previous research suggests that an employee's coping style is not a disposition and could be influenced by the contextual factors in work environment as well as individual-level factors (Carver et al., 1989; Folkman, 1992). We suggest that how managers treat and guide employees who are high on trait anger can determine the direction to which these employees will channel the emotional energy associated with their trait anger. For instance, when the managers stigmatize those employees with higher levels of trait anger and ignore their efforts to tackle work-related issues, these employees might be less likely to take on a problem-focused coping approach when they identify work-related problems, and thus engage in withdrawal work-behaviors. On the other hand, when the managers help employees with higher trait anger voice their concerns about organizational issues and effectively address their concerns, they can benefit from these employees' effort, insights, and determination to improve their organization. Our results also have implications for the anger management practices, which have gained an increasing level of popularity among business practitioners (Kassinove and Tafrate, 2010). Specifically, our study suggests that, although it has been originally formulated as a stress coping strategy, problem-focused coping can also be a useful method for employees to not only manage the tension associated with their anger but also actively pursue and solve work-related issues. 


\section{Acknowledgements}

This research project has been supported by the Research and Creative Activity Grant Program in California State University, Sacramento.

\section{References}

Aiken L. S., \& West, S. G. (1991). Multiple Regression: Testing and Interpreting Interactions. Newbury Park, CA: Sage.

Aquino, K., Lewis, M. U., \& Bradfield, M. (1999). Justice constructs, negative affectivity, and employee deviance: A proposed model and empirical test. Journal of Organizational Behavior, 20, 1073-1091.

Aristotle. 350 BCE/2004. The Nicomachean Ethics (J. A. K. Thompson, Trans.). New York: Oxford University Press.

Asforth, B., \& Humphrey, R. H. (1995). Emotion in the workplace: A Reappraisal. Human Relations, 48, 97-125.

Baron, M. R., \& Kenny. D. A. (1986). The moderator- mediator variable distinction in social psychological research: conceptual, strategic, and statistical considerations. Journal of Personality and Social Psychology, 51(6), 1173-1182.

Barsade, S. G., \& Gibson, D. E. (2007). Why do emotions matter in organizations? Academy of Management Perspectives, 21, 36-59.

Beal, D. J., Weiss, H. M., Barros, E., \& MacDermid, S. M. (2005). An episodic process model of affective influences on performance. Journal of Applied Psychology, 90, 1054-1068.

Berkowitz, L. (1990). On the formation and regulation of anger and aggression: A cognitive-neoassociationistic analysis. American Psychologist, 45, 494-503.

Brotheridge, C., \& Lee, R. T. (2003). "Testing a conservation of resources model of the dynamics of emotional labor", Journal of Occupational Health Psychology, 7(1), 57-67.

Booth, J., \& Mann, S. (2004). The experience of workplace anger. Leadership \& Organization Development Journal, 26, 250-262.

Brief, A. P, \& Weiss, H. M. (2002). Organizational behavior: Affect in the workplace. Annual Review of Psychology, 53, 279-30

Carver, C. S., Scheier, M. F., \& Weintraub, J. K. (1989) Assessing coping strategies: A theoretically based approach. Journal of Personality and Social Psychology, 56, 267-283

Collins, R. (1990). Stratification, emotional energy, and the transient emotions. In T. D. Kemper (Ed.), Research Agendas in the Sociology of Emotions, 27-57. Albany, NY: State University of New York Press.

Deffenbacher, J. L. (1992). Trait anger: Theory, findings, and implications. In C. D. Spielberger \& J. N. Butcher (Eds.), Advances in Personality Assessment, 9, 177-201. Hillsdale: Lawrence Erlbaum.

Deffenbacher, J. L., Getting, E. R., \& Thwaites, G. A. (1996). State-trait anger theory and the utility of the Trait Anger Scale. Journal of Counseling Psychology, 43, 131-148.

Douglas, S. C., \& Martinko, M. J. (2001). Exploring the role of individual differences in the prediction of workplace aggression. Journal of Applied Psychology, 86, 547-559.

Endler, N. S., \& Parker, J. D. A. (1990). Multidimensional assessment of coping: A critical evaluation. Journal of Personality and Social Psychology, 58, 844-854.

Fitness, J. (2000). Anger in the workplace: An emotion script approach to anger episodes between workers and their subordinates, co-workers and superiors, Journal of Organizational Behavior, 21, 147-162

Frijda, N. H. (1986). The Emotions. Cambridge, UK: Cambridge University Press.

Frijda, N. H. (1987). Emotion, cognitive structure, and action tendency. Cognition and Emotion, 1, 115-143.

Frijda, N. H., Kuipers, P., \& ter Schure, E. (1989). Relations among emotion, appraisal, and emotional action readiness. Journal of Personality and Social Psychology, 57, 212-228.

Folkman, S. (1982). An approach to the measurement of coping. Journal of Occupational Behavior, 3(1), 95-108.

Fox, S., Spector, P. E., \& Miles, D. (2001). Counterproductive work behavior (CWB) in response to job stressors and organizational justice: Some mediator and moderator tests for autonomy and emotions. Journal of Vocational Behavior, 59, 291-309.

Geddes, D. D., \& Callister, R. R. (2007). Crossing the line: Expressions of anger in organizations. Academy of 
Management Review, 32(3), 721-746.

Gibson, D., \& Callister, R. R. (2010). Anger in organizations: Review and critique. Journal of Management, $36,66-93$.

Gross, J. J., \& John, O. P. (2003). Individual differences in two emotion regulation processes: Implications for affect, relationships, and well-being. Journal of Personality and Social Psychology, 85, 348-362.

Hepworth, W., \& Towler, A. (2004). The effects of individual differences and charismatic leadership on workplace aggression. Journal of Occupational Health Psychology, 9, 176-185.

Izard, C. E. (1991). The Psychology of Emotions. New York: Plenum Press.

Kassinove, H., \& Tafrate, R. (2010). Anger Management: The Complete Treatment Guidebook for Practitioners. Atascadero, California: Impact Publiers.

Lazarus, R. S. (1999). Stress and Emotion: A New Synthesis. New York: Springer Publishing

Lazarus, R. S. (1991). Emotion and Adaptation. New York: Oxford University Press.

Lazarus, R., \& Cohen-Charash, Y. (2004). Discrete emotions in organizational life. In R. L. Payne \& C. L. Cooper (Eds.), Emotions at Work: Theory, Research and Applications for Management, 45-81. Chichester, UK: Wiley.

Lazarus R., \& Folkman S. (1984). Stress, Appraisal and Coping. New York: Springer.

Lindebaum, D., \& Fielden, S. (2011). 'It's good to be angry': Enacting anger in construction project management to achieve perceived leader effectiveness. Human Relations, 64(3), 437-458.

Mickel, A., \& Ozcelik, H. (2008). When executives get angry: The importance of anger and its triggers to ethical awareness and sensitivity. Neal Ashkanasy, Charime Härtel, \& Wilfred Zerbe, W. J. (eds.), Research on Emotions in Organizations, 4, 131-154. London: Emerald Publishing Group.

Morrison, E. W., \& Phelps, C. C. (1999). Taking charge at work: Extrarole efforts to initiate workplace change. Academy of Management Journal, 42, 403-419.

Pearson, C., Andersson, L., \& Porath, C. (2000). Assessing and attacking workplace incivility. Organizational Dynamics, Fall: 123-137.

Smith, C. A., \& Ellsworth P. C. (1985). Patterns of cognitive appraisal in emotion. Journal of Personality Social Psychology, 48, 813-838.

Smith, C. A., Haynes, K. N., Lazarus, R. S., \& Pope, L. K. (1993). In search of the 'hot' cognitions: attributions, appraisals, and their relation to emotion. Journal of Personality and Social Psychology, 65(5), 916-929.

Spielberger, C. D., Jacobs, G., Russell, S., \& Crane, R. S. (1983). Assessment of anger: The State-Trait Anger Scale. In J.N. Butcher \& C.D. Spielberger (eds.), Advances in Personality Assessment, 2, 159-187. Hillsdale, NJ: Erlbaum.

Schum, J. L., Jorgensen, R. S., Verhaeghen, P., Sauro, M., \& Thibodeau, R. (2003). Trait anger, anger expression and ambulatory blood pressure: A meta-analytic review, Journal of Behavioral Medicine, 26, 395-415.

Suls, J., Wan, C. K., \& Costa, P. T. (1995). Relationship of trait anger to resting blood pressure: A meta-analysis. Health Psychology, 14, 444-456.

Van Kleef, G. A., \& Côté, S. (2007). Expressing anger in conflict: When it helps and when it hurts. Journal of Applied Psychology, 92, 1557-1569.

Van Kleef, G. A., Van Dijk, E., Steinel, W., Harinck, F., \& Van Beest, I. (2008). Anger in social conflict: Cross-situational comparisons and suggestions for the future. Group Decision and Negotiation, 17, 13-30.

Wilkowski, B. M., \& Robinson, M. D. (2010). The anatomy of anger: An integrative cognitive model of trait anger and reactive aggression. Journal of Personality, 78, 9-38.

\section{$(\mathrm{cc}) \mathrm{BY}$}

This work is licensed under a Creative Commons Attribution 3.0 License 